\title{
Neiwan hydro powerhouse (A conceptual reconstruction study)
}

\author{
Štefan Tkáč ${ }^{1}$ \\ ${ }^{1}$ Department of Architectural Engineering, Technical University of Košice, Slovak Republic
}

Correspondence: Štefan Tkáč, ${ }^{1}$ Department of Architectural Engineering, Technical University of Košice, Vysokoškolská 4, 04200 Košice, Slovak Republic, Tel +421 (55)602 4261, Email stefan.tkac@tuke.sk

\section{Abstract}

The conceptual reconstruction of Neiwan powerhouse is one of the key activities under the current ongoing mapping project of Taiwanese hydropower plants that mainly took place between 2013 and 2015 and is now focused on micro, pico, and historical power plants.

Judging from the fact that the oldest hydropower plant in Taiwan named Guishan starts its operation in 1905 , Neiwan powerhouse was among the very first powerhouses that were built across the island to support the electrification of Taiwan. However, the main function of the single turbine equipped Neiwan micro powerhouse was to support mainly the military needs and protect the territories occupied by Japanese troops. Since the powerhouse was built in 1909 and operates only something about 10 year there are very little physical materials or evidence along with contemporaries. Therefore the further reconstruction is based mainly on physical observation of the remains located at the site, old photographs, related articles, treatises and typology of mechanical and civil constructions of other hydropower plant cases in Taiwan hence this paper's main intention is to pitch a concept reconstruction rather than definite conclusion.

2. Keywords: hydro-power; hydro-power plant; micro-energy; renewable energy; water energy

\section{Introduction}

The power generation in Taiwan could be dated back to 1888 when Chinese official from Qing Dynasty Liu Ming Chuan who was acting as a Taiwan Provincial Governor started the very first power company in Taiwan and introduced the technological advances including the el. energy on the island[1,2]. The hydropower generation, however, started during the early stage of Japanese colonization period in 1904 when the project of the very first hydropower plant named Guishan was commenced. The power plant was completed in 1905 which was a historical moment for Taiwanese energy generation. Thus it is safe to state that Taiwan got over 114years of hydropower generation history[3,4].
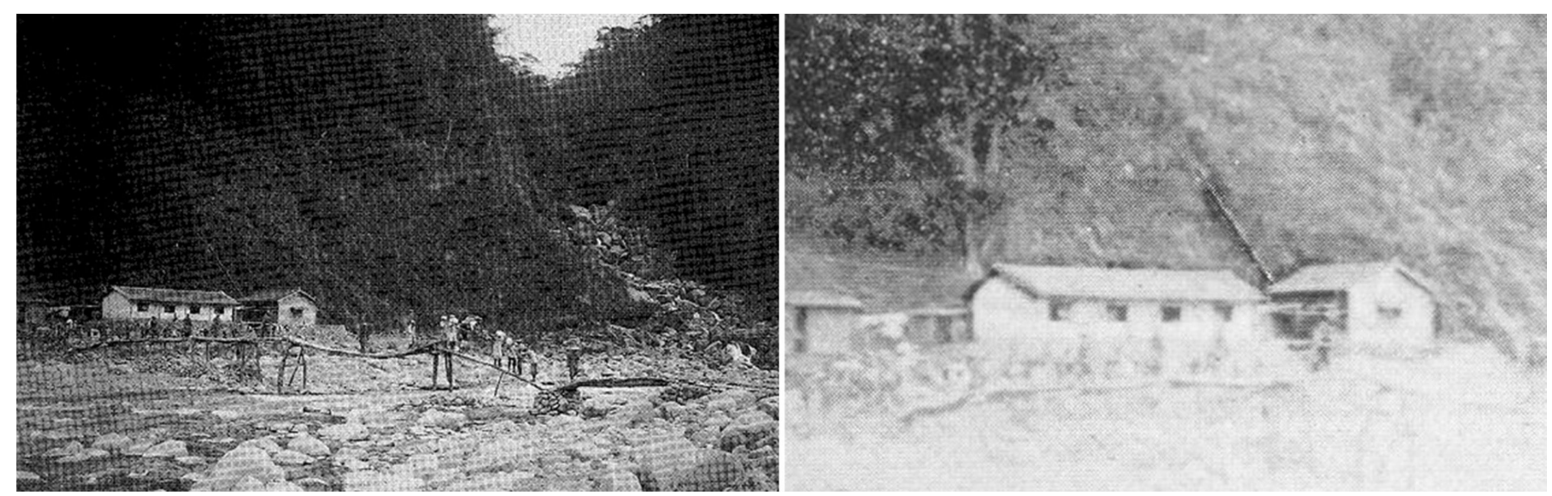

Figure 1: Analysis of the historical photograph of the Neiwan powerhouse from 1910 showing the communication bridge along the Hsinchu "Ài yǒng" line. The embankment and outflow are clearly visible on left. The penstock is purposely highlighted on the right close up. (Source: the photographs are based on the original imagery from the pictorial treatise about Taiwan during Japanese rule by the Japanese historian Okada Hidehiro[5] 
Based on the accessible materials the decision to build the Neiwan hydro powerhouse was made by the Taiwan Governor's Office to support the so-called "Li Fan" - the aboriginal policy during the Japanese occupation to suppress the Taiwanese aboriginal forces constantly attacking the Japanese outposts. The policy was implemented by using an electric fence to mark the commonly known "Ài yǒng" line[6] to keep the aboriginal tribes in the mountains. To power up the fence a power needed to be generated and Guishan powerhouse could not cover the entire fence due to distance and terrain, so series of small dispersed powerhouses were designed like Fanshekeng in Yilan(approx. 1907)[7], Neiwan in Hengshan(1910)[8] or Runchiao in Zhudong(1919)[9]. It is believed that there might be more of these houses as the "Ài yǒng" line was quite long, but the documents are still under research[10].

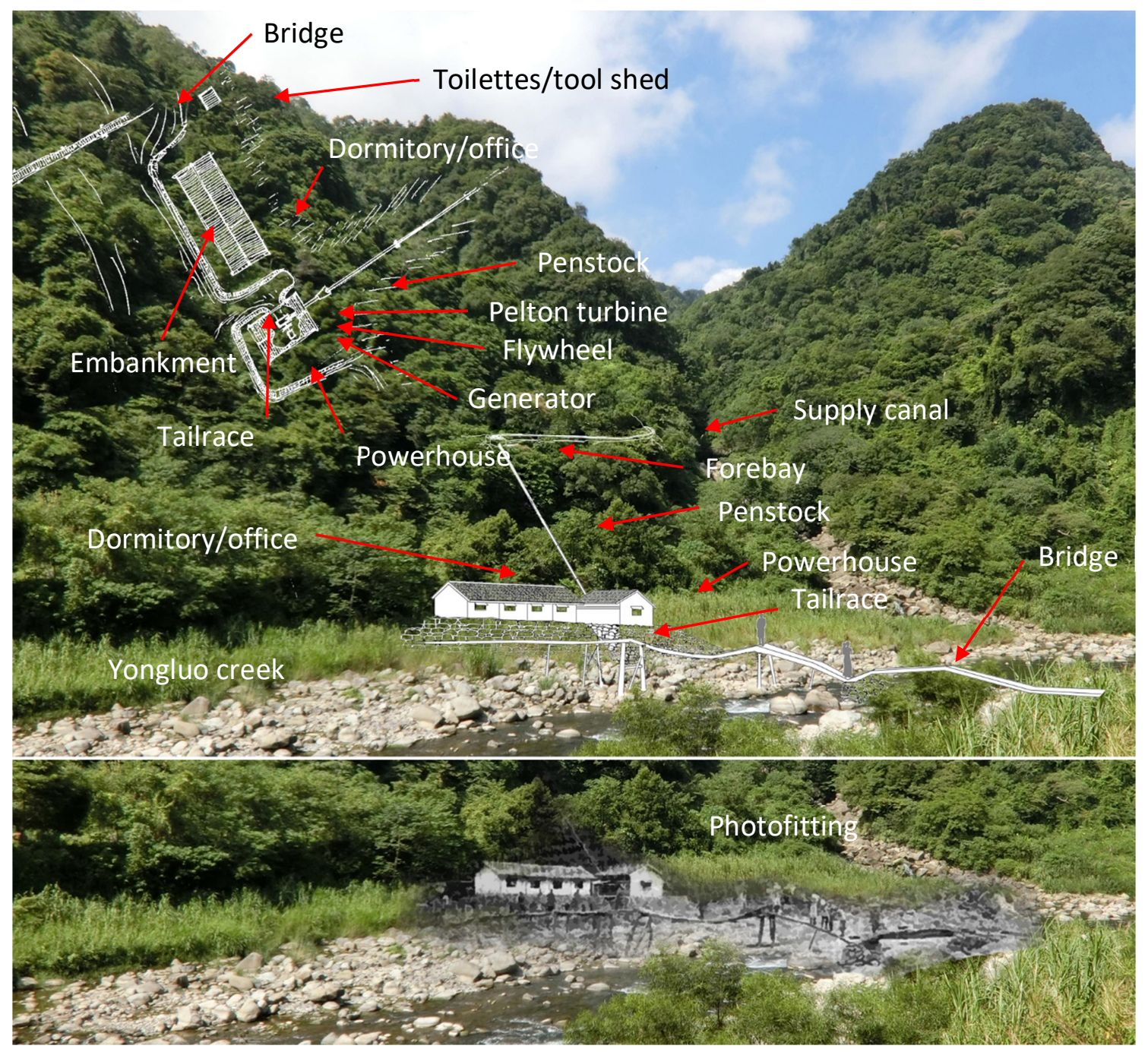

Figure 2: A conceptual reconstruction based on Hidehiro's pictorial treatise[5]

The construction works on Neiwan powerhouse were carried away between 1909 and 1910, only 4-5 years after the first Guishan powerhouse. Neiwan's turbine officially starts its operation from 1910 when on August $30^{\text {th }}$, the unfortunate flood caused by typhoon took place and the civil works had to be repaired. This cause an interruption of the power supply to the old Matai road which was one of the demarcation lines along the Hsinchu "Ài yǒng" line. This opportunity was used by the Atayal tribe to unsuccessfully attack the Japanese outposts and 
finally lost on October $16^{\text {th }}$. As a result, the Hsinchu "Ài yǒng” line was strengthened by a fort built on the Mount Lidong and the Neiwan powerhouse was rebuilt[11].

As the powerhouse was built on the side of the volatile Youluo creek after several successive floods, series of repair attempts and consecutive rose of the "Li Fan" policy, the Hsinchu "Ài yǒng" line lost it meaning and the powerhouse was slowly abandoned. The supply of energy to inhabitants was substituted by more powerful Runchiao powerhouse located over the mountain in Zhudong area which started operation in 1919[9].

The fact that Neiwan powerhouse was fulfilling its function only something about 8 years constantly interrupted by aboriginal attacks and repairs due to typhoon there are no maps showing the structure clearly. Also available maps from between 1909-1923 are only depicting the lands before the Hsinchu "Ài yǒng" line as the cartographers did not go deeper in the mountains. However there is a clear access path on the map from 1956 connecting the old Matai path with the lowlands on the left bank of the Yongluo creek, which means for the past decades people were still recognizing this area Fig. 3 mostly as an agricultural place.

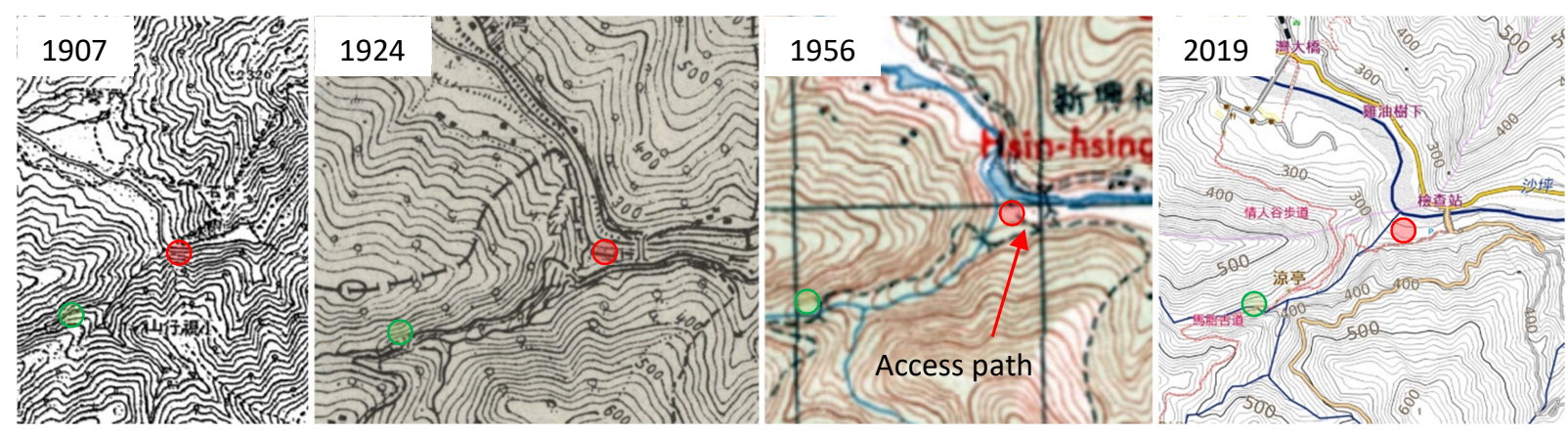

Figure 3: Comparison of the Neiwan powerhouse location pictured at the maps from1907,1924, 1956 and 2019. Maps based on Taiwan's century-old history map from the Center for GIS - Academic Sinica[12] (Red dot shows the location of the powerhouse and the green dot the location of the inflow)

\section{Methodology}

An on-site survey was carried away in three separate sessions, on August 25th, 2017, May 18th and 30th, 2018. As a result several remains of the water structures were found including the old stones with bamboo holes, intake opening, inflow canal and spillway Fig.4,5,6. All the elements were measured and documented. Pictures were taken during the all three mapping events. Gathered information was matched with available documents, historical maps and photograps to create a presumption about the water strucutres.

\section{Mapping, assessment and reconstruction}

The entire Neiwan powerhouse water structures started by naturally formed pond Fig.4. where a concrete spillway Fig.4. was constructed to divert water to the less steep bank on the right side of the valley. The diversion canal is still traceable Fig.4,5. Based on the on-site mapping results, there was and still is an inflow opening Fig.5. made of purposely scrapped $120 \times 40 \times 40 \mathrm{~cm}$ rocks that further led water into the headrace canal which was built along the old Matai road.

Here is where theory splits. After the intake opening the clear traces disappears thus there was either a supply canal which led the water down to the forebay and then to the penstock connecting the powerhouse but using up only about $20 \mathrm{~m}$ head between the forebay and the powerhouse or there was a second configuration. In this second option the Neiwan powerhouse was responsible for supplying the entire Hsinchu "Ài yŏng" line thus a strategic military element hence the theory that the power output had to be higher and the only way how to attain it was to use the entire head available. Thus in the second assumed configuration, there was a forebay after the intake that led water to the penstock right away without any supply canal. In this arrangement over $100 \mathrm{~m}$ head could bring around $200 \mathrm{~kW}$, sufficient to supply kilometers long electric fence lining the mountain crest. However this would be quite a unique solution as none of the other known powerhouses got this arrangement of the water structures plus it would be relatively difficult to get that long penstock in 1909 due to limited resources therefore further the first configuration with water supply canal will be discussed. 

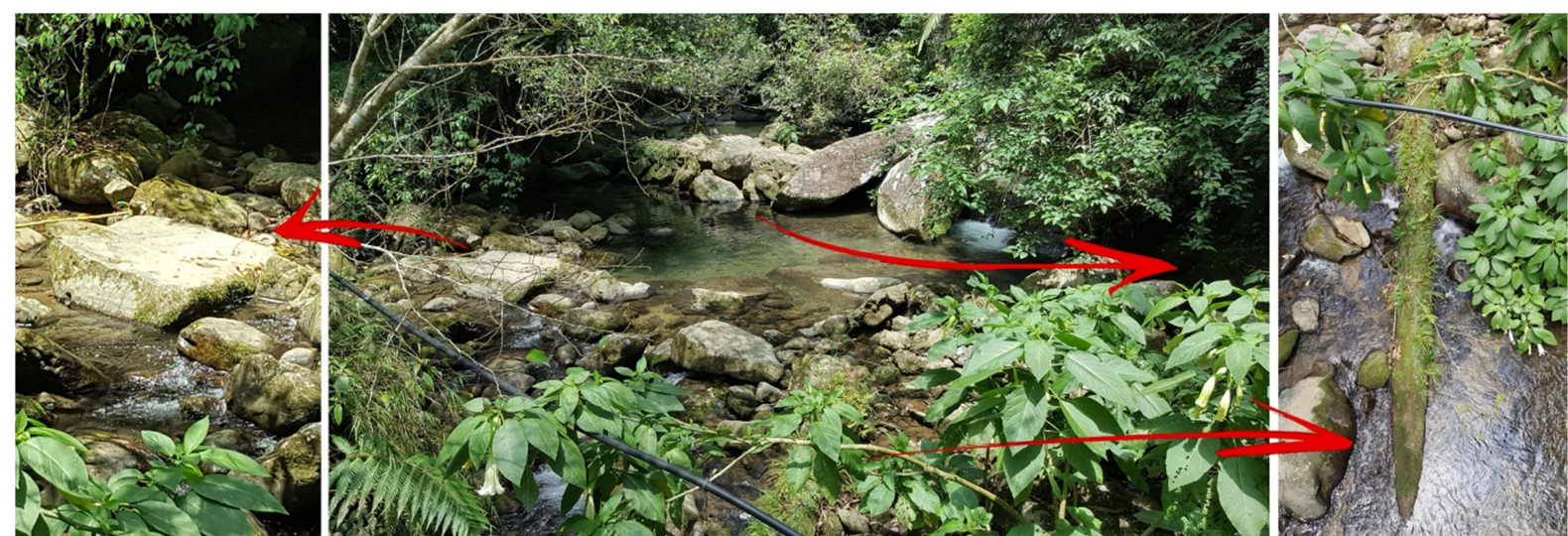

Figure 4: Former diversion weir. Elements of spillway could be found on left and right. Diversion canal is also clearly traceable however the entire riverbed use to be much higher judging from the current level of diversion canal and inflow opening(Source Author)

Continue with the first configuration after intake the water entered the supply canal following the forest path. This supply canal later crossed the original brook's valley most likely via aqueduct and brought water on left bank. Aqueducts are common structures included in waterworks of the hydro powerplants in Taiwan even these days thus is would be possible that older waterworks like those of Neiwan powerhouse were used as a structural models. What is more, there are dozens of rocks in the riverbed with clear artificial holes which could be residue of bamboo supports or before commonly used bamboo reinforced concrete. After passing the aqueduct water then continued along the forest path in the supply canal right to the forebay. After assumed forebay the water further continued by a slim penstock inclined in high angle down to the powerhouse. The penstock is clearly visible on the historical photograph Fig. 1. Based on the intake opening which was approximately $40 \mathrm{x} 40 \mathrm{~cm}$, the diameter was not bigger than DN300 with water discharge equal to $3001 / \mathrm{s}$ giving the machinery chance to have feasible installed capacity closing to $50 \mathrm{~kW}$ with output around $40 \mathrm{~kW}$ if assumed that head was up to $20 \mathrm{~m}$ and turbine efficiency around $70 \%$.
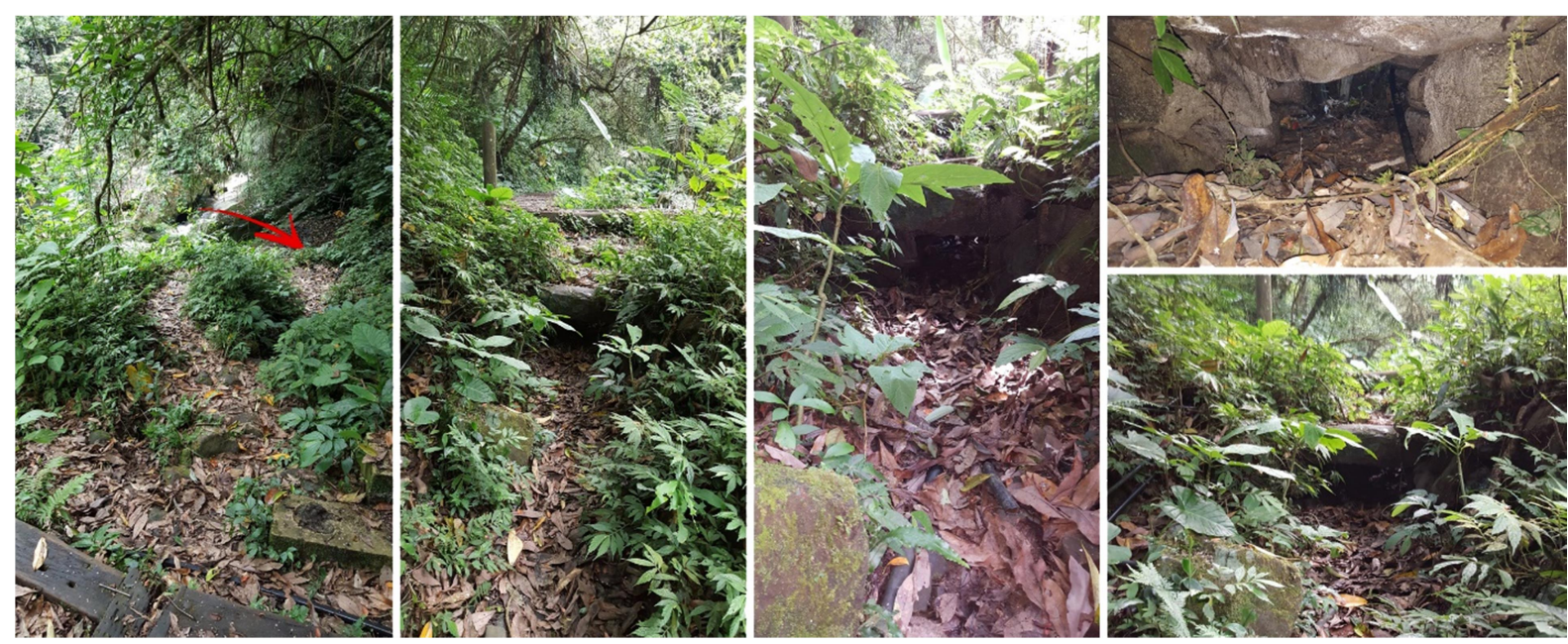

Figure 5: Diversion canal and inflow opening. The inflow is located few steps from the Matai forest path and it is clear that the further supply canal was following the path underneath the current pavement. 

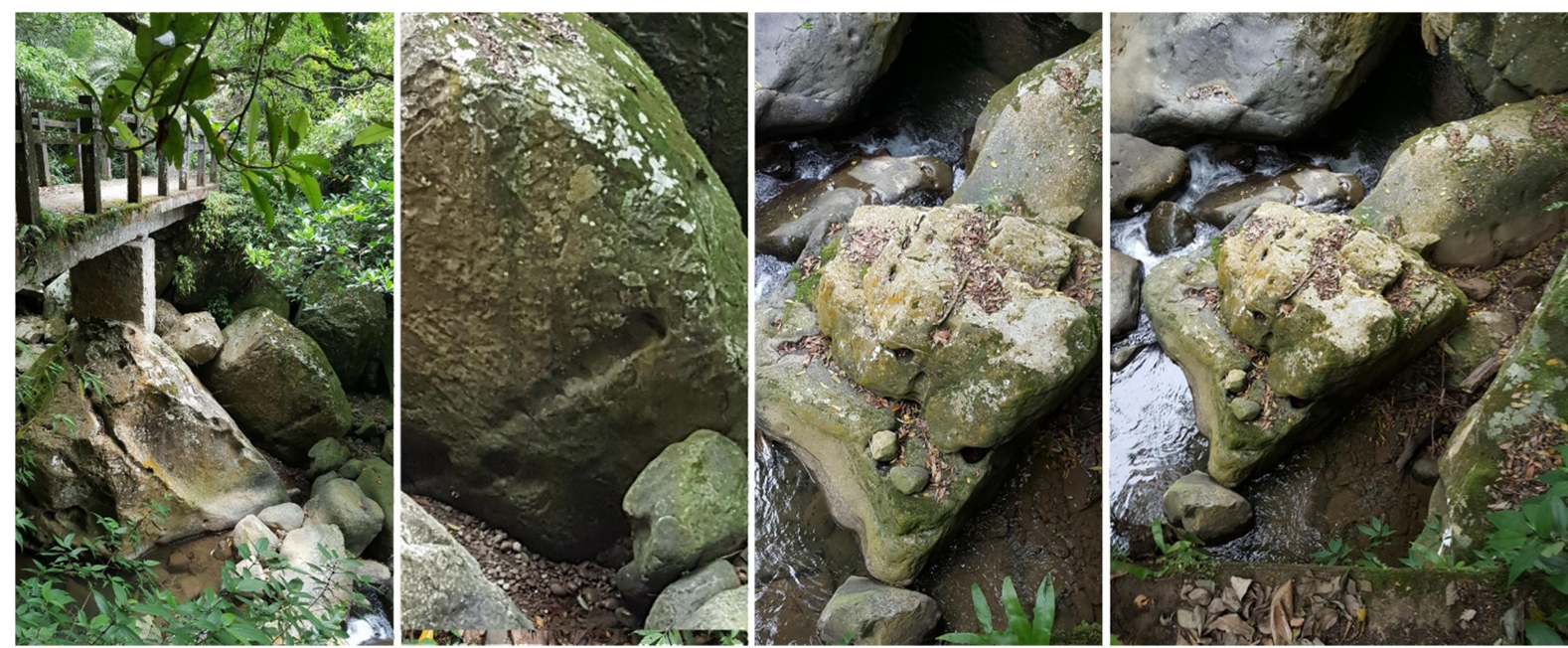

Figure 6: A series of stone marks around the current $2^{\text {nd }}$ bridge on Matai forest path showing traces of bamboo supports. During Japanese occupation period, due to lack of steel a bamboo reinforced concrete was quite common. Bridge no. 2 was also the place where supply canal crossed the valley most likely via aqueduct possibly supported by exactly bamboo reinforced concrete.

Based on analysis of the photography from Fig.1,2 and early Japanese concepts of high heads hydropower plants using slim and long penstock in Taiwan e.g. Sanjiaobu powerhouse in Tienmu[13], Taipei or much larger Qingshui unit[14], Neiwan has probably one of the early Pelton turbines. There is a high chance it was a single jet horizontal type with the previously mentioned installed capacity reaching $50 \mathrm{~kW}$. Also, most of the hydro turbines from that era got belt transmission, but since Pelton turbine is a high-speed impulse turbine there is a chance it was a direct drive microturbine with flywheel which are common in Taiwan. The fact that Neiwan has a Pelton turbine installed in confirms also the type of the outflow visible on the historical photograph Fig. 1,2 which is clearly above the Youluo creek ended up by a small waterfall between the actual powerhouse and the office building. A reaction turbine would have outflow below the Yongluo creek's water level due to water pressure equilibrium. Also, Pelton turbine would be easier to maintain given the conditions were Neiwan powerhouse was placed in.

\section{Results}

It is important to state that at this stage the research regarding the Neiwan micro hydro powerhouse is still incomplete, only the area assessment was managed and there is still a lot uncertainties yet to research until the final reconstruction could be carried away. The fact that Neiwan was a remote powerhouse and a key military object at the same time the only people that had access to the site and could legally photograph the building were Japanese soldiers or engineers thus this fact brings the biggest challenges in the entire research investigation.

\section{Discussion}

The hydropower topic is lately quite crucial in Taiwan due to the latest policy of denuclearization of the island. The truth is that Taiwanese HEP(Hydro energy potential) is not even used on $25 \%$ which is plaintively low in contrast to surrounding countries and the annual import rates of consumables are still reaching over $99 \%$. The search for alternatives and development of existing opportunities is thus vital. If it comes to hydropower plants in Taiwan, the good step forward could be the ongoing education in high school and public sector via series of practical action workshops to raise the awareness. Also the National Taiwan Energy company Taipower with IPP (Individual Power Producers) policy loosen the monopoly on energy generation which already brought around 6 private hydropower projects and $7^{\text {th }}$, the Mudan powerplant is on its way. Then there are several serious pico hydro projects, but mostly serving as an attraction in local farms, but there is extensive research on hydropower potential of the irrigation canals. On the national level, also there are renovation and retrofitting activities including research on Variable speed control PS hydro and their possibility to store volatile wind power from the wind farms into the Mitang or 
Daguan PS hydro powerplants. Ultimately there is one national hydro powerplant project around the Carp Reservoir which will complete the cascade together with the exhisting Lanyang hydro powerplant.

\section{Conclusion}

Although this paper provides answers only to limited amount of questions regarding the Neiwan powerhouse it is still incredible that there are some water structures still visible even after 110years. This can give away at least the evidence of the quality of work even on provisory structures like border powerhouse made of limited materials mostly available on site including handmade and imported technology of the time.

9. Funding details: This paper was funded by the National Stipend Fund of the Slovak Republic.

\section{Acknowledgments:}

Here I would like to express my deepest gratitude to everyone that helps me along my work on the unique complex project about Taiwanese hydropower plants titled: "Mapping of the Taiwanese hydropower plants" which lasts over 6years and has been supported by the National Stipend Fund of the Slovak Republic, ERASMUS+ KA107, Post-doctor Visegrad-Taiwan Scholarship, Technical University of Kosice, Chung Hua University, National Chiao Tung University, Chinese Institute of Civil and Hydraulic Engineering and Taipower.

The overall mapping book titled "Taiwanese hydropower plants in detail" is scheduled for release at the end of 2019 and Neiwan case will be one of the included studies thus I would also like to recognize all involved in making of this publication.

My ultimate thank goes to my fellow researcher and friend Mr. Deng Zhongwen, with whom we cooperate on assessment of historical hydropower plants files and with whom I share the same passion for Taiwan hydropower plants research.

11. Conflict of interests: Author declares that there is no conflict of interest, all used historical pictures are subject to Articles 30 to 34 of the Republic of China Copyright Law, and Article 23 of the Japanese Copyright Law and Article 2 of the Supplementary Provisions of the Japanese Copyright Law. The on-site mapping photographs are author's original work. The maps were retrieved from the Center for GIS, RCHSS Academic Sinica provinding free access to the Taiwan's historical map layers for research purposes. The portal was fully recognized within references.

\section{References}

[1] Cheng, G. "Talking about the past and present of Taiwan's electric industry." WordPress.com, Retrieved February 2, 2019, from https://gordoncheng.wordpress.com/2014/07/30/漫談台灣電業的前世今生上/

[2] Fairbank, K.J, Liu, K.C., The Cambridge history of China, Volume 11 Late Ching1800-1911, Part 2. Cambridge University Press: Cambridge; 1980.

[3] Lin B. Y., The beginning of Taiwan's experience - the history of Taiwan Power Co., Ltd.. Taiwan Power Co., Ltd. Company Information Center, 1997.

[4] Tkac, Š, Taiwanese hydropower plants - photo guide. China Institute of Civil and Hydraulic Engineering: Taipei; 2016.

[5] Higehiro, O. Takamatsunomiya kashi no Memorial photograph book, Taiwan during japanese rule. (2007). Retrieved 19.1.2019, from https://ci.nii.ac.jp/els/contents1 10006388856.pdf?id=ART0 008387161

[6] Huang, W. L., "Emergence and Legal treatment of "Flatland aboriginals" during Japanese rule 19851937." Taiwan Historical Research. Volume 19. Issue 2 (2012): Page(99-150). Retrieved January 7, 2019, from http://lawdata.com.tw/tw/detail.aspx?no=214409

[7] Ko, T (2014, 7. 26.). Fanshekeng hydropower house. 17.6.2018 from https://kotaine.blogspot.com /2014/07/blog-post_26.html 
[8] Lin, B.L (2008, 1. 29.). Neiwan Power Station Site. 17.6.2018 from https://blog.xuite.net/evanhoe/balihun/15526726

[9] Lin, B.Y (2008, 3. 12.). Jiangjian's Policy, Runchiao Hydropower Station. 17.6.2018 from https://pylin.kaishao.idv.tplaintivelyw/?p=455

[10] Deng, Z. W. (2018) Talk about 100 years of Taitung Electric Industry development: 100 years of power development. Taitung City, Taiwan: Taitung District Office of Taiwan Power Company.

[11] Ministry of Education R.O.C.(2016). The Battle of Li Yishan. The Dictionary of Taiwan's Aboriginal History and Culture, Retrieved February 1, 2019, from http://210.240.125.35/ citing/citing_content.asp?id=3882\&keyword=0A7\%F5\%D4\%F8\%A4s\%BE\%D4\%A7\%D0

[12] Center for GIS, RCHSS Academic Sinica (2019). Taiwan's century-old history map. Retrieved January 4, 2019, from http://gissrv4.sinica.edu.tw/gis/twhgis.html

[13] Lin, B.Y (2008, 3. 12.). Notes about Sānjiăobu Hydropower house. 17.6.2018 from https:// pylin .kaisha o.idv.tw/?p=1138

[14] Lin, B.Y (2009, 4. 20.). Qingshan station the first powerhouse. 22.1.2019 from https:// pylin.kaishao.idv.tw/?p=1272 